\title{
(2) OPEN ACCESS \\ Colonic angiodysplasia: a culprit of obscure gastrointestinal bleeding in a patient with Heyde syndrome
}

\author{
Ming Yoke Vera Shaw, ${ }^{1}$ Ravishankar Asokkumar, ${ }^{2}$ Emile John Tan Kwong Wei, ${ }^{1}$ \\ Isaac Seow-En (1) ${ }^{1}$
}

${ }^{1}$ General Surgery, Singapore General Hospital, Singapore ${ }^{2}$ Gastroenterology, Singapore General Hospital, Singapore

\section{Correspondence to} Dr Ming Yoke Vera Shaw; verashaw@yahoo.com.sg

Accepted 23 December 2021

\begin{abstract}
SUMMARY
A 77-year-old woman presented with obscure gastrointestinal bleeding requiring multiple hospitalisations and blood transfusions. The patient underwent repeated investigations over four hospital admissions across a span of two months. These included upper and lower gastrointestinal endoscopy, video capsule endoscopy as well as CT enterography, without definitive localisation or treatment of the source of bleeding. Finally, a technetium-99m-labelled red blood cell scan demonstrated a 'blush' at the proximal transverse colon on delayed imaging. Targeted colonoscopic evaluation showed a subcentimetre angiodysplastic lesion in the corresponding spot at the proximal transverse colon with slow persistent oozing. Endoscopic clips were applied with successful haemostasis. The patient recovered well without further symptom recurrence 5 months postdischarge. We review the literature on colonic angiodysplasias and discuss the diagnostic challenges in obscure gastrointestinal bleeding.
\end{abstract}

\section{BACKGROUND}

The American Gastroenterological Association (AGA) defined occult gastrointestinal (GI) bleeding in a 1999 position statement as a positive faecal occult blood test result with or without iron-deficiency anaemia. ${ }^{1}$ Obscure GI bleeding is defined as persistent or recurrent bleeding from a GI source that is not readily identifiable following gastroscopy and colonoscopy, with the addition of small bowel radiologic evaluation in the 2007 AGA position statement update. ${ }^{2}$ Obscure GI bleeding can be further categorised into obscure overt or obscure occult bleeding depending on the presence or absence of clinically evident bleeding.

Proving that a lesion found during GI evaluation is conclusively responsible for the bleeding that has been highlighted as an issue during the diagnostic process. Zuckerman and Prakash used the example of attributing haematochezia to diverticulosis found on colonoscopy to illustrate this point. ${ }^{3}$ Incorrect diagnoses can frequently be made on early endoscopic assessment for bleeding, and many patients have more than one lesion, which may be responsible for lower GI haemorrhage. ${ }^{45}$

Angiodysplasias can be found throughout the GI tract, increasing in incidence with advancing age. The term is synonymous with arteriovenous malformation (AVM), angiectasia and vascular ectasia. These are the most common vascular anomalies of the GI tract and are well-known causes of both occult and obscure GI bleeding. ${ }^{2}$

Angiodysplastic lesions discovered incidentally on colonoscopy should not be treated in patients who do not have an appropriate history of GI bleeding or anaemia. However, treatment should be instituted if occult or overt bleeding is present.

\section{CASE PRESENTATION}

A 77-year-old woman presented with 2 months history of intermittent painless per rectal bleeding and symptoms of anaemia. The character of bleeding ranged from fresh to dark red and mixed in the stools.

Her previous medical history was significant for hypertrophic obstructive cardiomyopathy with moderate aortic stenosis, hypertension and hyperlipidaemia. She also had diabetes mellitus with diabetic nephropathy, resulting in stage 4 chronic kidney disease not yet requiring dialysis.

\section{INVESTIGATIONS AND TREATMENT}

The patient had a total of four hospitalisations for bleeding within a span of 2 months. In total, 11 units of packed red blood cells were administered to her during this period. Haemoglobin level ranged from $6.0 \mathrm{~g} / \mathrm{dL}$ to $10.3 \mathrm{~g} / \mathrm{dL}$. Baseline serum creatinine level was 150 to $160 \mathrm{umol} / \mathrm{L}$.

She was initially admitted from the emergency department for a history of fresh blood mixed in with stools for several days as well as symptomatic anaemia. She underwent colonoscopy, which showed fresh blood streaks from the proximal ascending colon to rectum. Small, congested haemorrhoids were seen. No diverticulosis or neoplasia was found on colonoscopy. Her symptoms were attributed to haemorrhoids, and she was counselled accordingly. Bleeding had resolved and stools were normal prior to discharge.

She represented 3 weeks later for recurrent bleeding and anaemia. Flexible sigmoidoscopy was performed with rubber band ligation of haemorrhoids. In addition, gastroscopy was performed, which was normal up to the second part of the duodenum. As before, her symptoms resolved, and she was discharged well.

Her third presentation occurred another 3 weeks later with dark altered per rectal bleeding. In view of her chronic renal impairment, the patient was advised on the risk of 

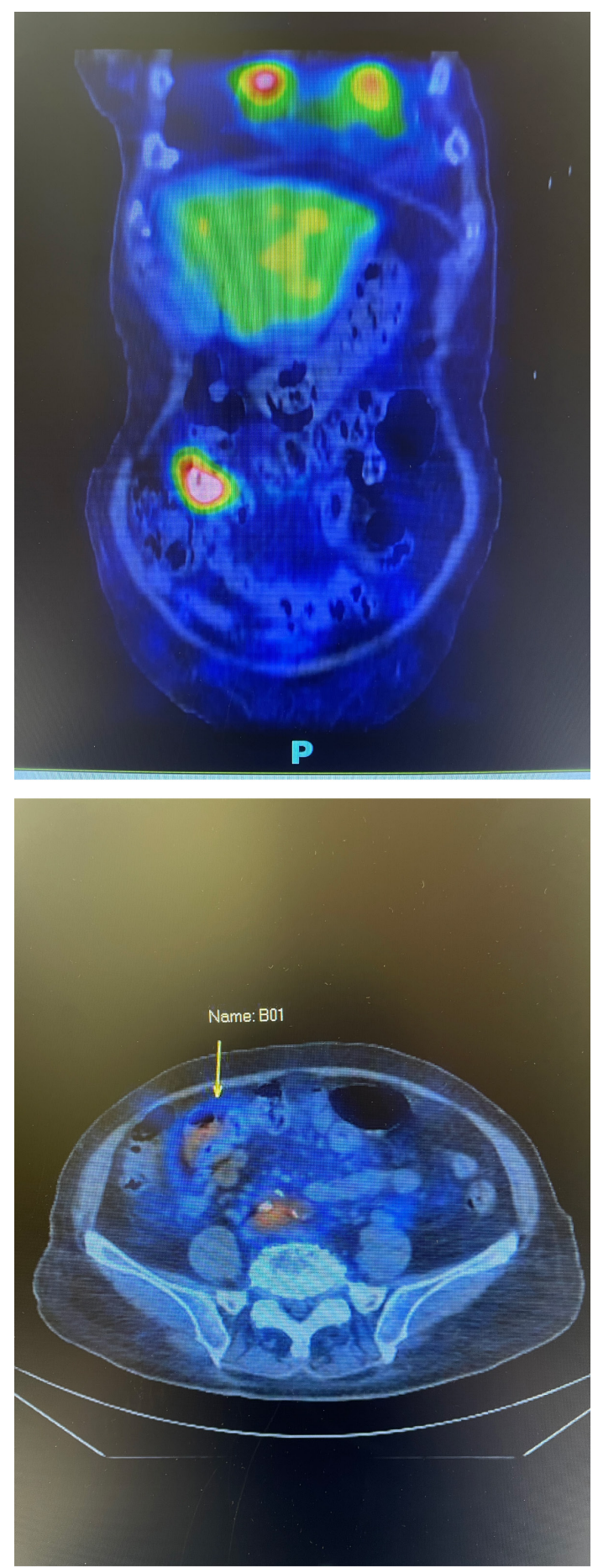

Figure 1 Technetium-99m pertechnetate radionuclide study showing tracer accumulation on the patient's right localising to the distal transverse colon.

contrast-induced nephropathy, prior to CT enterography, which showed jejunal diverticulum and ileitis. However, there was no contrast blush or pooling to suggest active bleeding. She was given a course of oral antibiotics for treatment of the enteritis and discharged following the passage of regular stools without the presence of blood.

The patient again presented to the emergency department 10 days later for symptomatic anaemia and dark red stools. Urgent colonoscopy was performed less than 2 hours from admission. Stale blood streaks were observed from the

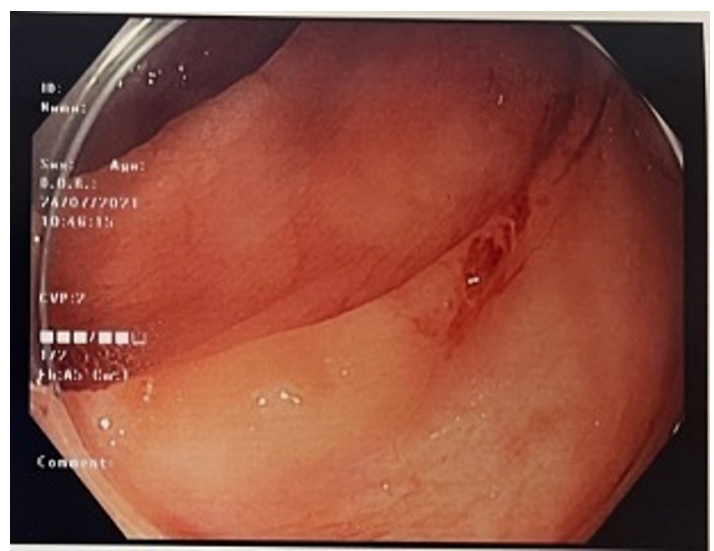

Figure 2 Slow-oozing transverse colon angiodysplastic lesion seen on colonoscopy.

rectum to the proximal ascending colon with brown stools in caecum. The terminal ileum was intubated with no blood or other lesions observed. Despite inadequate bowel preparation, the colon was thoroughly inspected for diverticulum and angiodysplasia, which were not seen. A gastroscopy was also repeated which was normal. Thereafter, a capsule endoscopy was performed, which showed acute superficial duodenal erosions and small bowel diverticulosis but no blood nor angiodysplastic lesions. At this point, the patient's bleeding had once again spontaneously resolved.

Finally, the patient underwent scintigraphy after modified in vivo labelling of red blood cells using $22.7 \mathrm{mCi}$ of technetium- $99 \mathrm{~m}$ pertechnetate. First, a dynamic $60 \mathrm{~min}$ acquisition of the abdomen and pelvis was obtained, followed by static delayed images obtained up to 4.5 hours. Single-photon emission CT (SPECT) of the abdomen and pelvis was performed at 4 hours. Delayed static images at 3.5 hours revealed a suspicious focus of tracer accumulation, which localised to the transverse colon on SPECT (figure 1). Prompt colonoscopy with careful inspection of the mucosa indicated on the scan showed an AVM (figure 2), with very slow oozing. Haemostasis was achieved with the application of four endoscopic clips (figure 3).

\section{DIFFERENTIAL DIAGNOSIS}

For this case of obscure GI bleeding, the general surgeons were involved in her care for her first two admissions, followed by the colorectal surgeons and gastroenterologists for her third and fourth admissions.

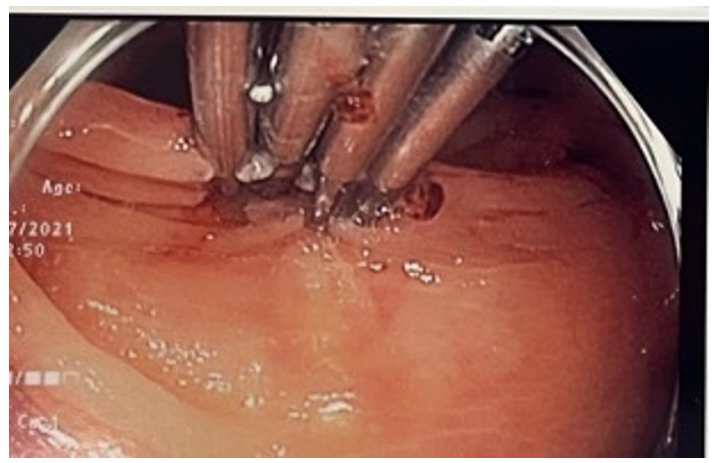

Figure 3 Haemostatic clips applied to the colonic arteriovenous malformation. 
Various diagnoses were considered, including haemorrhoidal bleeding, posthaemorrhoidal wound bleeding, small or large intestine diverticulosis or angiodysplasia, peptic ulcer disease as well as enteritis.

\section{OUTCOME AND FOLLOW-UP}

The patient was observed in hospital for 48 hours postprocedure, with no further bleed or drop in haemoglobin. She was discharged and found to remain symptom free at the outpatient clinic review 2 weeks later. There has been no recurrence of bleeding at 5 months postendoscopic therapy.

\section{DISCUSSION}

Within the GI tract, angiodysplasias are most often in the large intestine, with majority occurring on the right side of the colon. They have an $8 \%$ prevalence among healthy asymptomatic patients aged above 50 years old ${ }^{6}$ and account for $3 \%-12 \%$ of acute lower GI bleeding. ${ }^{3}$ Angiodysplasia has been associated with several systemic diseases, including end-stage renal failure, ${ }^{7}$ and aortic stenosis, ${ }^{8}$ both of which are present in our patient. GI bleeding from angiodysplasia in the presence of aortic stenosis is known as Heyde syndrome, after Edward Heyde who first described the association in 1958. ${ }^{9}$

The pathophysiology of angiodysplasia remains unclear. Proposed theories include chronic intermittent low-grade venous obstruction, resulting in dilatation of the submucosal veins and development of abnormal arteriovenous communications. ${ }^{10}$ Other hypotheses include the involvement of angiogenic factors ${ }^{11}$ as well as the association with aortic stenosis caused by a depletion of von Willebrand factor in blood flowing through a narrowed valvular stenosis.

The sensitivity of colonoscopy for detecting angiodysplasia compared with angiography was found to be $81 \% .^{12}$ Angiodysplasias are small, flat and cherry-red on endoscopic appearance, typically less than $10 \mathrm{~mm}$ in size. ${ }^{6}{ }^{13}$ Small lesion size, location behind a mucosal fold, or suboptimal bowel preparation during an emergent procedure may decrease the sensitivity of colonoscopic evaluation. Adding to the difficulty of detection is the natural history of angiodysplasia bleeding, which is typically slow, venous and intermittent. The low bleeding rate may also reduce the accuracy of multiphase CT angiography and formal angiography, which localise bleeding only if the rate of blood loss is greater than 0.3 to $0.5 \mathrm{~mL} / \mathrm{min}$ and 0.5 to $1.0 \mathrm{~mL} / \mathrm{min}$, respectively. ${ }^{14} 15$

Radionuclide scanning is the most sensitive radiographic test for GI bleeding, able to detect bleeding greater than a $0.1 \mathrm{~mL} /$ min. ${ }^{16}$ After injection of the technetium- $99 \mathrm{~m}$ pertechnetatelabelled red cells, a 60-minute dynamic scan is obtained, followed by static 2D planar images at intervals for several hours if no tracer accumulation is seen on the initial dynamic study. If bleeding is suspected on subsequent static imaging, an SPECT is performed for more accurate localisation. For these reasons, scintigraphy is useful for patients with obscure and intermittent bleeding, including those with suspected GI angiodysplasia. The 1999 AGA algorithm suggests a nuclear scan following upper and lower GI endoscopy for obscure overt GI bleeding. ${ }^{1}$ The disadvantage of a radionuclide scan is the inability to perform therapy, and a positive scan should be followed up shortly with angiography or colonoscopy for haemostasis. Delaying the therapeutic procedure may reduce the window for localisation and management of the lesion due to the intermittent nature of bleeding.
Various modalities have been used for treatment of bleeding angiodysplasias, including administration of octreotide or hormonal therapy, angiographic embolisation, endoscopic methods or surgical resection. ${ }^{317}$ Of the endoscopic techniques, argon plasma coagulation and bipolar or heater probe electrocoagulation have been best described in the literature, ${ }^{3}{ }^{18}$ with argon plasma coagulation recommended as first-line endoscopic therapy. ${ }^{19}$ Mechanical haemostasis with endoscopic clips has not been well reported. Takahashi et al previously documented a case of successful endoscopic clipping for bleeding from colonic angiodysplasia in a case of Heyde syndrome. ${ }^{20}$ Aortic valve replacement has been shown to improve angiodysplastic bleeding in patients with aortic stenosis, ${ }^{8}$ although the angiodysplasia has been reported to persist months later. ${ }^{21}$

A 2014 meta-analysis of 831 patients with angiodysplasia, including 623 patients treated via endoscopy, showed a 36\% rebleeding rate at a median of 22 months from endoscopic therapy. ${ }^{17}$ It may, therefore, be important to follow-up these patients over the longer-term.

\section{Learning points}

Endoscopic assessment for gastrointestinal (GI) bleeding may reveal more than one potential pathology, resulting in misdiagnoses or diagnostic delay. A high index of suspicion is required and additional or repeat evaluation may be necessary to definitively identify the lesion(s) responsible.

- Angiodysplasias are relatively common in the older population of patients. However, incidentally discovered lesions do not need treatment.

- Angiodysplasia bleeding is associated with several systemic diseases, including end-stage renal failure and aortic stenosis. In patients with aortic stenosis, aortic valve replacement has been shown to improve angiodysplastic bleeding.

- Radionuclide scintigraphy is the most sensitive test for $\mathrm{Gl}$ bleeding and is especially useful for patients with obscure and intermittent sources of bleeding.

- While argon plasma coagulation and electrocoagulation are the best-described methods for endoscopic treatment of bleeding angiodysplasias; endoclip application can be successful for haemostasis.

Contributors MYVS: contributed to the drafting and revision of the manuscript and agreement to be accountable for all aspects of the work. RA: contributed to the conception of the manuscript. EJTKW: contributed by giving the final approval for the manuscript to be published. IS-E: contributed to the conception and revision of the final manuscript.

Funding The authors have not declared a specific grant for this research from any funding agency in the public, commercial or not-for-profit sectors.

Competing interests None declared.

Patient consent for publication Consent obtained directly from patient(s) Provenance and peer review Not commissioned; externally peer reviewed.

Open access This is an open access article distributed in accordance with the Creative Commons Attribution Non Commercial (CC BY-NC 4.0) license, which permits others to distribute, remix, adapt, build upon this work non-commercially, and license their derivative works on different terms, provided the original work is properly cited and the use is non-commercial. See: http://creativecommons.org/ licenses/by-nc/4.0/.

Case reports provide a valuable learning resource for the scientific community and can indicate areas of interest for future research. They should not be used in isolation to guide treatment choices or public health policy.

\section{ORCID iD}

Isaac Seow-En http://orcid.org/0000-0001-8287-6812 


\section{REFERENCES}

1 American gastroenterological association medical position statement: evaluation and management of occult and obscure gastrointestinal bleeding. Gastroenterology 2000;118:197-200.

2 Raju GS, Gerson L, Das A, et al. American gastroenterological association (AGA) Institute medical position statement on obscure gastrointestinal bleeding. Gastroenterology 2007;133:1694-6.

3 Zuckerman GR, Prakash C. Acute lower intestinal bleeding. Part II: etiology, therapy, and outcomes. Gastrointest Endosc 1999:49:228-38.

4 Vellacott KD. Early endoscopy for acute lower gastrointestinal haemorrhage. Ann $R$ Coll Surg Engl 1986;68:243-4.

5 Caos A, Benner KG, Manier J, et al. Colonoscopy after Golytely preparation in acute rectal bleeding. J Clin Gastroenterol 1986;8:46-9.

6 Foutch PG, Rex DK, Lieberman DA. Prevalence and natural history of colonic angiodysplasia among healthy asymptomatic people. Am J Gastroenterol 1995;90:564-7.

7 Chalasani N, Cotsonis G, Wilcox CM. Upper gastrointestinal bleeding in patients with chronic renal failure: role of vascular ectasia. Am J Gastroenterol 1996;91:2329-32

8 Mohee K, Aldalati O, Dworakowski R, et al. Aortic stenosis and anemia with an update on approaches to managing angiodysplasia in 2018. Cardiol J 2020;27:72-7.

9 Heyde EC. Gastrointestinal bleeding in aortic stenosis. The New England Journal of Medicine 1958:259:196.

10 Boley SJ, Sammartano R, Adams A, et al. On the nature and etiology of vascular ectasias of the colon. degenerative lesions of aging. Gastroenterology $1977 ; 72: 650-60$.
11 Junquera F, Saperas E, de Torres I, et al. Increased expression of angiogenic factors in human colonic angiodysplasia. Am J Gastroenterol 1999;94:1070-6.

12 Richter JM, Hedberg SE, Athanasoulis CA, et al. Angiodysplasia. clinical presentation and colonoscopic diagnosis. Dig Dis Sci 1984;29:481-5.

13 Krevsky B. Detection and treatment of angiodysplasia. Gastrointest Endosc Clin N Am 1997:7:509-24.

14 Kuhle WG, Sheiman RG. Detection of active colonic hemorrhage with use of helical CT: findings in a swine model. Radiology 2003:228:743-52.

15 Walker TG. Acute gastrointestinal hemorrhage. Tech Vasc Interv Radiol 2009:12:80-91.

16 Dusold R, Burke K, Carpentier W, et al. The accuracy of technetium-99m-labeled red cell scintigraphy in localizing gastrointestinal bleeding. Am J Gastroenterol 1994:89:345-8.

17 Jackson CS, Gerson LB. Management of gastrointestinal angiodysplastic lesions (GIADs): a systematic review and meta-analysis. Am J Gastroenterol 2014;109:474-83.

18 Kwan V, Bourke MJ, Williams SJ, et al. Argon plasma coagulation in the management of symptomatic gastrointestinal vascular lesions: experience in 100 consecutive patients with long-term follow-up. Am J Gastroenterol 2006;101:58-63.

19 García-Compeán D, Del Cueto-Aguilera Ángel N, Jiménez-Rodríguez AR, et al. Diagnostic and therapeutic challenges of gastrointestinal angiodysplasias: a critical review and view points. World J Gastroenterol 2019;25:2549-64.

20 Takahashi N, Tanabe K, Yoshitomi H, et al. Successful endoscopic clipping for bleeding from colonic angiodysplasia in a case of Heyde syndrome. Med Sci Monit 2010;16:CS107-9.

21 Akutagawa T, Shindo T, Yamanouchi K, et al. Persistent gastrointestinal angiodysplasia in Heyde's syndrome after aortic valve replacement. Intern Med 2017;56:2431-3.

Copyright 2021 BMJ Publishing Group. All rights reserved. For permission to reuse any of this content visit https://www.bmj.com/company/products-services/rights-and-licensing/permissions/ BMJ Case Report Fellows may re-use this article for personal use and teaching without any further permission.

Become a Fellow of BMJ Case Reports today and you can:

- Submit as many cases as you like

- Enjoy fast sympathetic peer review and rapid publication of accepted articles

- Access all the published articles

- Re-use any of the published material for personal use and teaching without further permission

\section{Customer Service}

If you have any further queries about your subscription, please contact our customer services team on +44 (0) 2071111105 or via email at support@bmj.com.

Visit casereports.bmj.com for more articles like this and to become a Fellow 